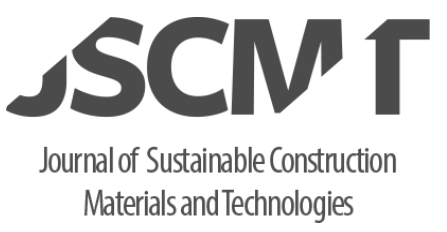

J. Sustain. Construct. Mater. Technol. 1(2) (2016) 46-56
Journal of Sustainable Construction Materials and Technologies

www.eds.yildiz.edu.tr/jscmt

\title{
An Experimental Investigation of the Effect of Depth and Diameter of Pre-drilling on Friction Drilling of A7075-T651 Alloy
}

\author{
Zülküf Demir ${ }^{1, *}$ \\ ${ }^{1}$ Faculty of Technology, University of Batman, Batı Raman Campuse, Batman, Turkey
}

Received April 4, 2016, accepted May 30, 2016

\begin{abstract}
Friction drilling is a non-traditional drilling process, in which specimens are drilled by means of frictional heat, which is obtained from friction effect in between rotating conical tool and workpiece area. The main purpose of current study was to investigate the effect of pre-drilling depth and diameter on the bushing shape, initial deformation and frictional heat in friction drilling of A7075-T651 aluminum alloy, known as a brittle material. Results showed that the effect of pre-drilling depended on the geometrical dimensions of the tip of the tool. The initial deformation was reduced, frictional heat was generated regularly and bushing shape was in the form of cylindrical with less cracks and petal formation in conditions predrilling diameter close to the end diameter of the tip of the tool and pre-drilling depths bigger than its length. The highest temperature was recorded at $3000 \mathrm{rpm}$ spindle speed and $40 \mathrm{~mm} / \mathrm{min}$ feed rate.
\end{abstract}

Keywords: Friction drilling; Pre-drilling diameter and depth; Initial deformation; Temperature, Bushing shape

\section{Introduction}

Friction drilling is a non-traditional, thermal, flow, form or friction stir drilling method, in which it has nochip, no pollution, short machining time, and long tool life [1-4]. In the process, a bushing forms from thinwalled workpiece. The help of bushing increases the thickness of threading and clamp load of thin-walled materials. Cracks and petal formation, which generate a bushing with limited surface area, come into existence in ductile material encompassing the tool, the brittle one begins to fracture during friction drilling processes [2].

The thermal properties of work-materials affect the frictional heating. High thermal conductivity of the workpiece reduces the temperature and ductility for bushing formation. During the friction drilling process, the frictional heat dissipates into the tool, workpiece, and their surroundings [1]. The maximum temperature generated in friction drilling is noticed to be about $1 / 2$ to $2 / 3$ of the work-material melting temperature, thus the melting temperature of the work-material also becomes important. At the elevated temperatures, the plasticity of the work-material has increased while the fracture has decreased. The temperature of the tool and the workpiece is high and the workpiece deformation is very large in friction drilling [2].

As the strain of bushing reaches a critical level, the bushing burst into petals. Petal formation decreases under great ration of the thickness of the workpiece to the hole diameter $(\mathrm{t} / \mathrm{d})$. Pre-heating of brittle workpiece causes more cylindricality, less fracture to decrease cracks, petal formation, and radial displacement of bushing. The main reason for the deformation of the workpiece and tool wearing is stress-strain, which occurs during the friction drilling process [2].

\footnotetext{
* Corresponding author: Tel.: +90-488-217-4023.

E-mail address: zulkuf.demir@batman.edu.tr (Z. Demir)

https://doi.org/10.29187/jscmt.2017.5
} 
While the high feed rates cause incomplete melting of the workpiece, the slow feed rates cause internal melting temperature of the material having different cooling speeds. When the feed rates are too slow or too fast, an uneven melting temperature is obtained from friction drilling process. Spindle speed is the most significant parameter, which causes to obtain more heat in friction drilling process [5]. The frictional heat transfer to the tool and the workpiece increases at high spindle speeds, thus the workpiece temperature increases during the process [6]. The contact, due to the effect of friction, which generates frictional heat, increases in between rotating conical tool and workpiece when the spindle speed is increased per unit time, thus the hole area temperature increases. As the shear stress and the friction coefficient, which is in between conical tool and workpiece, drop, the temperature increases [7]. In friction-drilling process, when the number of holes drilled increase, the surface temperature of tool increases as well, and this leads to a high surface roughness of conical tools. The temperature obtained at high spindle speeds reduces the hardness of the cutting tool, which causes to undermine its wear resistance. At high rotation speeds, more frictional heat energy is produced, and melting occurs on large area of both workpiece and tool being heated and hole wall to achieve better roundness. However, the effect of feed rate on the results is less than rotating speed, mentioned above [8].

The deformation of workpiece is very severe at the stage of the tip of tool region proceeding into the workpiece in friction drilling (Miller et al., 2007). Increases in conical angle cause to increase distortions in washer geometry because of extrusion forces act on workpiece by rotating conical tool [9]. Surface delaminating occurs with severe scoring and plastic deformation, which have micro cracking below the deformed layer in friction drilling of Al5052 [10\}.

The geometry of friction drilling tool, as called the tip, conical and cylindrical regions, affects the hole inner diameter, bushing shape, and cylindricality of the hole [11]. High tool conical angles cause the pressure in a narrower area between rotating conical tool and workpiece. Thus, the workpiece is to be drilled swiftly and the contact, which is in between tool and workpiece, decreases during the operation. However, it has not a significant effect on the results of friction drilling such as temperature, bushing shape, surface roughness, and cylindricality of the friction-drilled hole [12].

Pre-drilling eliminates the initial deformation and provides an appropriate melting temperature, in contrast to in pre-drilling friction drilling; there is a friction heat deficiency. With choosing higher spindle speeds, the deficiency of heat can be compensated [13].

The main purpose of this experimental study was to investigate the effect of both the depth and diameter of traditionally pre-drilling on the frictional heat, bushing shape, and the initial deformation in friction drilling of A7075-t651 aluminum alloy, which can be classify as a brittle material. The specimens were prepared traditionally pre-drilled with HSS (High Speed Steel) drills in diameters of 1.5, 2, 2.5, 3, 3.5 and $4 \mathrm{~mm}$ and in depths of 1, 2, 3 and $4 \mathrm{~mm}$.In addition, the experiments applied to the specimens, which were not pre-drilled. During the operations, the temperature of the workpiece, which was friction drilled at 8 and $10 \mathrm{~mm}$ in diameter, was measured by using two different kinds of thermocouples. The thermocouples were inserted into the workpiece, on both sides, which were $8 \mathrm{~mm}$ (right side) and $9 \mathrm{~mm}$ (left side) $\mathrm{mm}$ away from the centre of the friction-drilled hole of $8 \mathrm{~mm}$ in diameter. On the other hand, they were inserted into the workpiece, on both sides, which were $9 \mathrm{~mm}$ (right side) and $10 \mathrm{~mm}$ (left side) for the workpiece with a friction-drilled hole of $10 \mathrm{~mm}$ in diameter.

\section{Materials and Methods}

HESSAP True-Trace C-360 3D 1095 Model Copy milling machine was used for the friction drilling, in which the specimens were without pre-drilling and traditionally pre-drilled $1.5,2,2.5,3,3.5$, and $4 \mathrm{~mm}$ in diameters, and 1, 2, 3, and $4 \mathrm{~mm}$ in depths. Spindle speeds of 1800, 2400, and $3000 \mathrm{rpm}$, and feed rates of 40, 60 , and $80 \mathrm{~mm} / \mathrm{min}$ were as operating conditions due to choose. The experimental set up is shown in Fig. 1. The A7075-T651 aluminum alloy specimens, which were $6 \mathrm{~mm}$ in thickness, were prepared in size of 70x500 $\mathrm{mm}$, were used in experimental study having a composition of $0.08 \% \mathrm{Si}, 0.28 \% \mathrm{Fe}, 1.67 \% \mathrm{Cu}, 0.61 \% \mathrm{Mn}$, $2.37 \% \mathrm{Mg}, 0.19 \% \mathrm{Cr}, 5.76 \% \mathrm{Zn}, 0.036 \% \mathrm{Ti}$, balance (89.004) Al by weight.

The rotating conical tool was manufactured from HSS with the following dimensional characteristics 8 and $10 \mathrm{~mm}$ in diameters (d), $36^{\circ}$ conical angle (B), and $16 \mathrm{~mm}$ cylindrical region length (hl). The pictures of the tools, which were $8 \mathrm{~mm}$ in diameter is seen in Fig. 2 (a) and $10 \mathrm{~mm}$ in diameter in Fig. 2 (b), additionally, their geometrical dimensions are seen in Fig. 2 (c). The length of the tip of the tool, which was $8 \mathrm{~mm}$ in diameter, was $1.40 \mathrm{~mm}$ and the other tool, which was $10 \mathrm{~mm}$ in diameter, was $1.75 \mathrm{~mm}$ in length of the tip. 


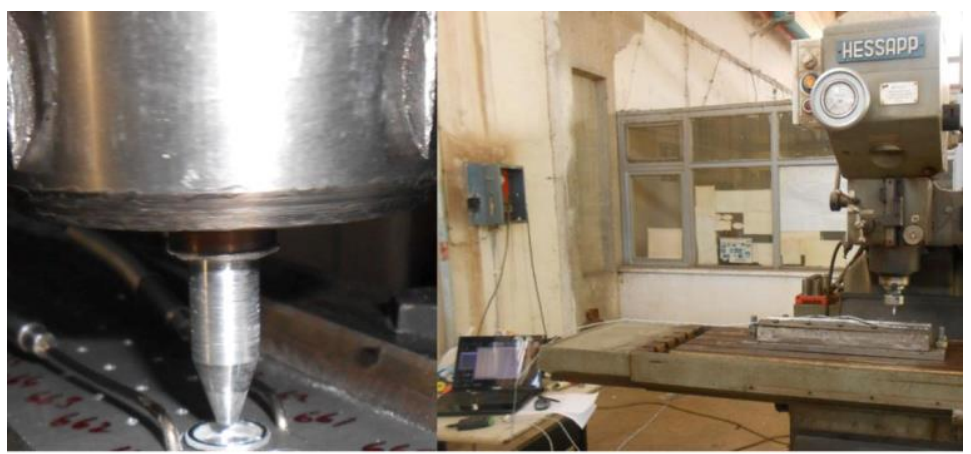

Figure 1- Experimental set up.

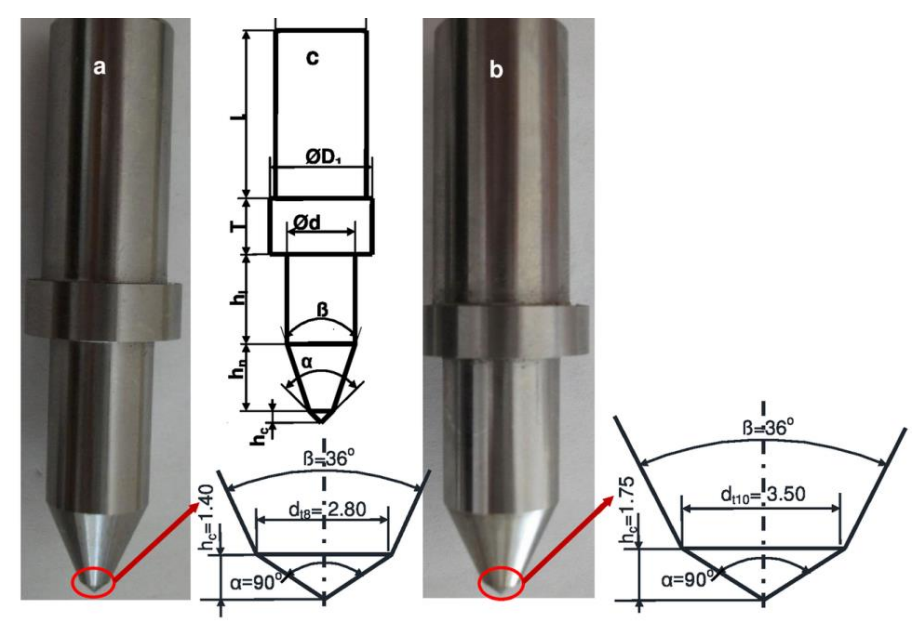

Figure 2-Geometrical dimensions of conical tools and their tips, a) the tool $8 \mathrm{~mm}$ in diameter, b) the tool $10 \mathrm{~mm}$ in diameter, c) geometrical dimensions of friction-drilling tools.

During the experimental study, the frictional heat was measured by using two different kinds of thermocouples. The thermocouples were inserted into the workpiece as shown in Fig. 3 (a, b).

Before applying friction drilling to specimens, they were pre-drilled at four different depths and six different diameters as seen in Fig. 4 (a, b), Fig. 4 (a) as indicated $8 \mathrm{~mm}$ and Fig. 4 (b) $10 \mathrm{~mm}$ in diameters friction drilled holes. The pre-drilling depths were symbolized as $\mathrm{t}_{0}=0, \mathrm{t}_{1}=1, \mathrm{t}_{2}=2, \mathrm{t}_{3}=3$, and $\mathrm{t}_{4}=4 \mathrm{~mm}$, while the diameters were $\mathrm{d}_{0}=0, \mathrm{~d}_{1}=1.5, \mathrm{~d}_{2}=2, \mathrm{~d}_{3}=2.5, \mathrm{~d}_{4}=3, \mathrm{~d}_{5}=3.5$, and $\mathrm{d}_{6}=4 \mathrm{~mm}$. The contact area, represented with surrounding by green lines, in between the tip of tool and workpiece, causes initial deformation, as shown in Fig.4 (a, b). The depths and diameters are shown in Fig. 4 (a), which are less than $1.40 \mathrm{~mm}$ in depths and $2.8 \mathrm{~mm}$ in diameters for $8 \mathrm{~mm}$ in diameter friction drilled holes, while in Fig. 4 (b) they are exhibited less than 1.75 in depths and $3 \mathrm{~mm}$ in diameters for $10 \mathrm{~mm}$ in diameter friction drilled holes.

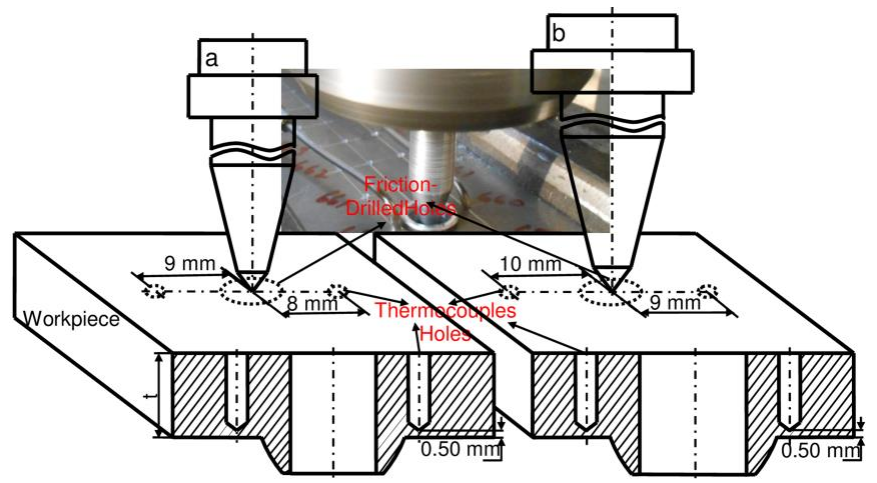

Figure 3-The thermocouples set up a) for $8 \mathrm{~mm}$ in diameter friction-drilled hole, b) $10 \mathrm{~mm}$ in diameter frictiondrilled hole. 


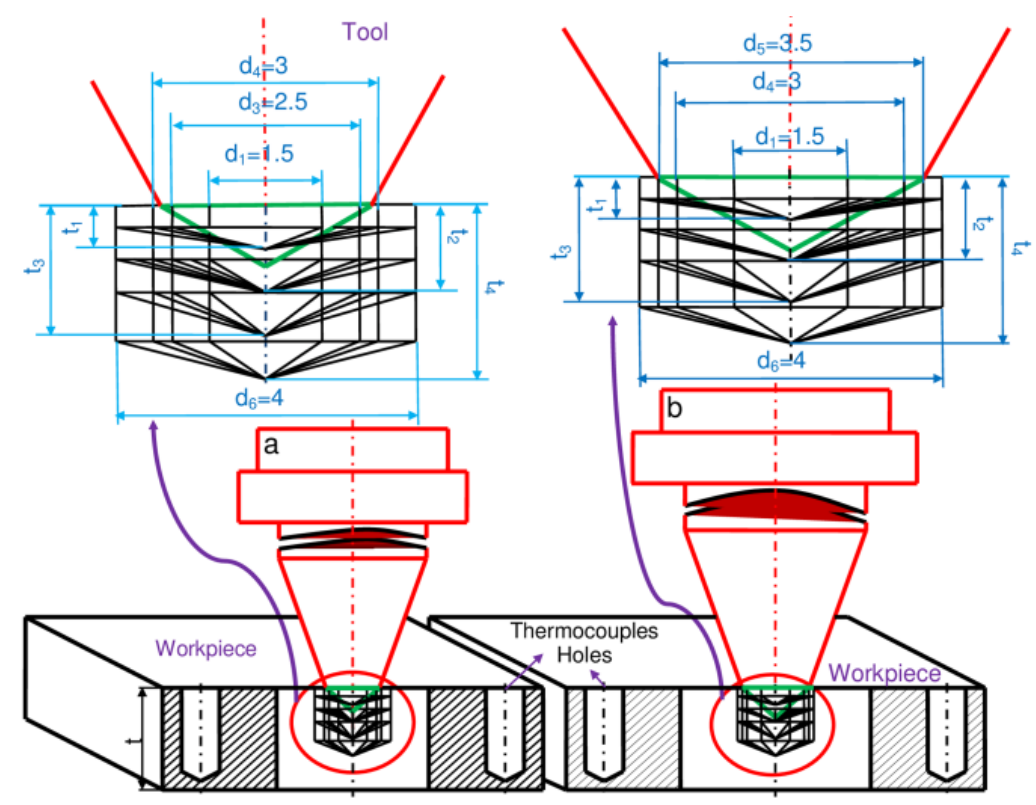

Figure 4-The depths and the diameters of pre-drilling a) for $8 \mathrm{~mm}$ in diameter and b) for $10 \mathrm{~mm}$ in diameter friction-drilled holes.

\section{Results and Discussion}

\subsection{The effect of pre-drilling depths and diameters on the initial deformation}

In friction drilling, the initial deformation is vitally important to affect the results of the process such as bushing shape and temperature. Therefore, in order to investigate the effect of pre-drilling depth and diameter on the bushing shape and frictional heat, at the beginning stage, the pictures of friction drilling process were captured in the first four seconds duration. The effects of pre-drilling depths and diameters on the initial deformation, in conditions at different spindle speeds and feed rates, are shown in Fig. 5 and 6, indicating 8 mm and $10 \mathrm{~mm}$ in diameters friction drilled holes, respectively.

Friction drilling operations were carried out by using tools, which were manufactured from HSS $8 \mathrm{~mm}$ and 10 $\mathrm{mm}$ in diameters, additionally, with $1.40 \mathrm{~mm}$ and $1.75 \mathrm{~mm}$ lengths and $2.80 \mathrm{~mm}$ and $3.50 \mathrm{~mm}$ end diameters of the tips of the tips, as shown in Fig. 4 (a) and (b), respectively. According to the pictures, which were captured in 4 seconds from the time as soon as the tip of the tool touched to the workpiece surface (see Fig. 5 and 6), the initial deformation decreased as the length and end diameter of the tip of the tool was closer to the pre-drilling depths and diameters. No sooner had the tip of the tool contacted on the surface of the workpiece, than deformation started and material moved off from the sample in the case of without pre-drilling $(\mathrm{d} 0=0, \mathrm{t} 0=0)$ friction drilling. The severity of the deformation continued until the amount of frictional heat, which was generated, by the contacting effect between tool and workpiece, reached to about $1 / 2$ to $2 / 3$ of the work-material melting temperature. After the amount of frictional heat reached to the melting level, mentioned above, the process temperature was started generating regularly, however, with generating regular frictional heat, the severity of the deformation decreased. By the effect of deformation and moment of rotating conical tool, the material, which was broken from the specimen, was surrounded around the tip of the tool, as seen in Fig. 5 and 6 . However, in case of pre-drilling, the contacting the tip of the tool on the workpiece started at the depths $(1,2$, 3 and $4 \mathrm{~mm}$ ) of pre-drilled and when the peripheral diameter of the tip of the tool was equal to the pre-drilled diameters $(1.5,2,2.5,3,3.5$ and $4 \mathrm{~mm})$. As seen in Fig. 5 and 6,the effect of initial deformation decreased with less cracks, decelerations and petal formation, in case of specimens, were pre-drilled higher than $1.40 \mathrm{~mm}$ and $1.75 \mathrm{~mm}$ in depths and $2.5-3 \mathrm{~mm}$ and $3.5 \mathrm{~mm}$ in diameters for $8 \mathrm{~mm}$ and $10 \mathrm{~mm}$ in diameters friction drilled holes, respectively. However, the number of the cracks and decelerations increased with increasing both spindle speed and feed rate, which created momentum and driving force, in turn. In conditions specimens were predrilled higher than $3 \mathrm{~mm}$ and $3.5 \mathrm{~mm}$ in diameters for $8 \mathrm{~mm}$ and $10 \mathrm{~mm}$ in diameters friction drilled holes, respectively, deformation was started at the depth where the pre-drilling diameter was equal to the peripheral 
diameter of the tip of the tool. In case of the specimens were pre-drilled at $3.5 \mathrm{~mm}$ and $4 \mathrm{~mm}$ in diameters for 8 $\mathrm{mm}$ and $4 \mathrm{~mm}$ in diameter for $10 \mathrm{~mm}$ in diameters friction drilled holes, respectively, and at depths higher than 2 $\mathrm{mm}$, cracks and petal formation generated on bushing shape and washer, because of insufficient soften and flown material. Nevertheless, in case of pre-drilling diameters were smaller than $2.80 \mathrm{~mm}$ and $3.50 \mathrm{~mm}$ for $8 \mathrm{~mm}$ and $10 \mathrm{~mm}$ in diameters friction drilled holes, respectively, as soon as the tip of the tool touch to the workpiece, with the effect of impacting, the severity of deformation increased depending on magnitude of spindle speed and feed rate. At the beginning stage of friction drilling, because the softening and flowing of the material did not start, the generation of cracks, decelerations and petal formation increased on the washer, which came into existence from the material flown upward.

The material, which flowed upward to shape the washer, was increased with increasing the diameter of friction-drilled holes. As seen in Fig.6, the volume of material, which flowed upward, in 4 seconds from the time the tip of the tool contacting on the workpiece, increased in friction drilling of $10 \mathrm{~mm}$ in diameter, because of increasing peripheral size of the drilled hole. At the constant material thickness $(6 \mathrm{~mm})$, with increasing the diameter of friction-drilled holes, because of insufficient material, which shaped the washer and bushing, cracks, decelerations and petal formation increased. Additionally, the number of cracks increased with increasing spindle speed and feed rate, with the effects of momentum and driving force, respectively. Therefore, in order to drill large diameter holes, great material thicknesses should be selected in friction drilling operations.

Consequently, the pictures in Fig. 5 and 6 showed that, pre-drilling provided a soften transition between the tip and conical regions of the tool, during its proceeding into the workpiece. As pre-drilling diameter was close to the end diameter of the tip and pre-drilling depth was higher than the length of the tip (hc), the initial deformation decreased in pre-drilling friction drilling of A7075-T651 aluminum alloy.

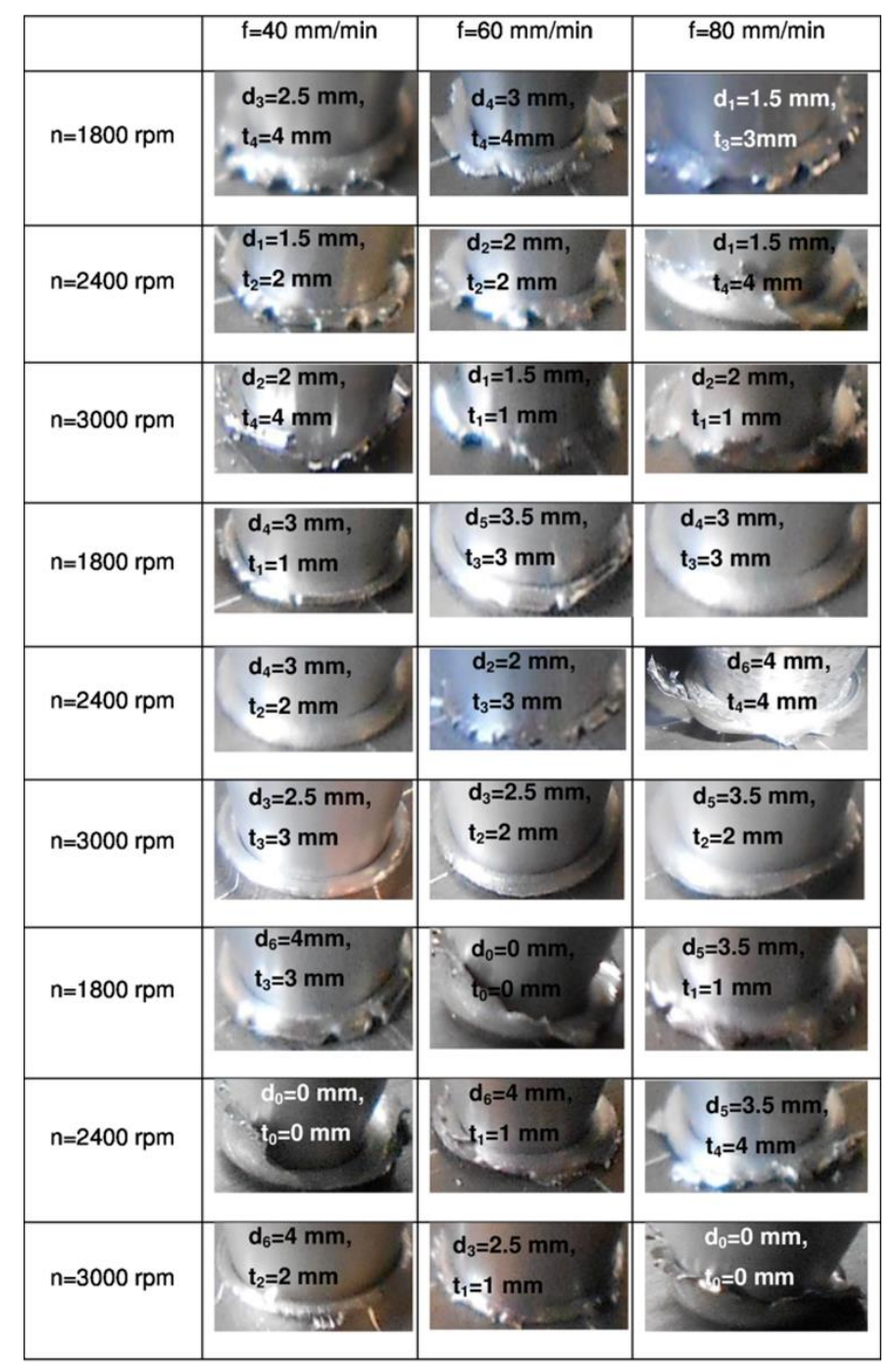

Figure 5-The effect of initial deformation (in the first four seconds) for $8 \mathrm{~mm}$ in diameter friction drilled holes. 


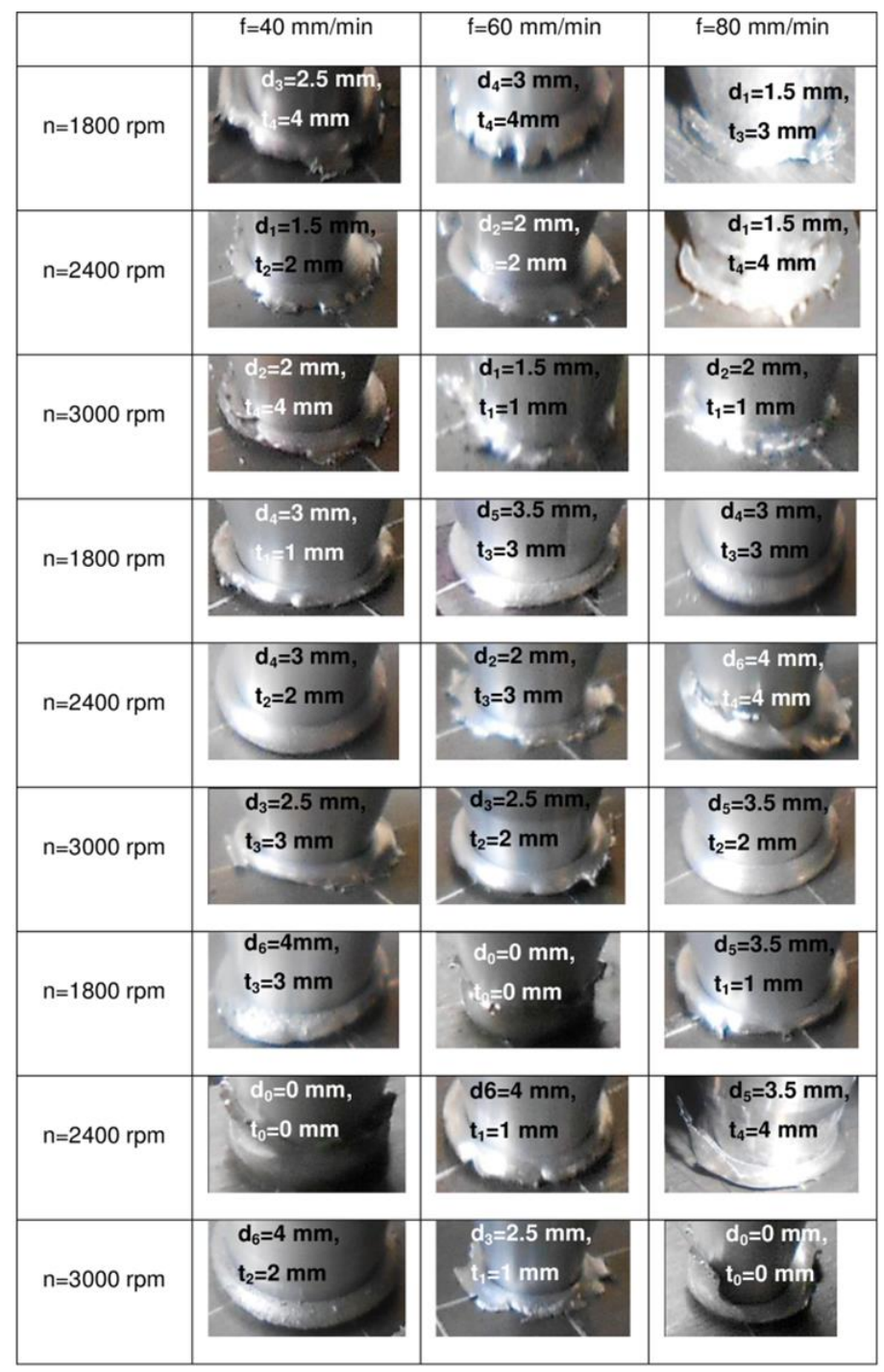

Figure 6-The effect of initial deformation (in the first four seconds) for $10 \mathrm{~mm}$ in diameter friction drilled holes.

\subsection{The effect of pre-drilling depths and diameters on the bushing shapes}

Friction drilling is a non-traditional drilling method, which can be applied to sheet cast material, on the purpose of increasing threading height and clamp load, in case of connecting two or more parts, by virtue of bushing shape underside of the material, thus, the bushing shape has a vital importance in the process. In the bushing shape, cracks and petal formation come into existence in friction drilling of brittle materials, while ductile materials are more appropriate than brittle ones to obtain cylindrical bushing shape with less or without cracks and petal formation. On the purpose of achieving cylindrical bushing, shapes with less or without cracks and petal formation, in friction drilling of A7075-T651 alloy, which is known as a brittle material, specimens were traditionally pre-drilled at the stage of preparation. The effect of pre-drilling depths and diameters on the bushing shapes is shown in Fig. 7 and 8 , for $8 \mathrm{~mm}$ and $10 \mathrm{~mm}$ in diameters, friction drilled holes, respectively, at different spindle speeds and feed rates.

As the length and diameter of the tip of the tool was close to pre-drilling depths and diameters, as seen in Fig. 7 and 8, the bushing shape improved in cylindrical form with less cracks and petal formation. Because of the initial deformation, the length of cracks on the bushing shapes increased in friction drilling, in which specimens were not pre-drilled. According to the pictures of bushings in Fig 7 and 8, when the depths of pre-drilling were higher than $1.40 \mathrm{~mm}$ and $1.75 \mathrm{~mm}$, the diameters of pre-drilling were $2.5-3 \mathrm{~mm}$ and $3.5 \mathrm{~mm}$ for $8 \mathrm{~mm}$ and 10 $\mathrm{mm}$ in diameters friction drilled holes, respectively, the bushing shapes were consisted of cylindrical form with less cracks and petal formation.

The cracks and deceleration in bushing shapes increased with increasing both spindle speed and feed rate. 
However, in conditions specimens pre-drilled at 3.5 and $4 \mathrm{~mm}$ in diameters for $8 \mathrm{~mm}$ and $4 \mathrm{~mm}$ for $10 \mathrm{~mm}$ in diameters friction drilled holes, even at low spindle speeds and feed rates, bushing shapes distorted, in which cracks and petal formations occurred, because of insufficient softened and flowed material. Because either predrilling eliminated or reduced the deformation, which came into effect during the tool progressing into the workpiece, the bushing shape came into existence cylindrically and with less or without cracks and petal formation. Throughout the friction-drilling operation from the time the tip of the tool contacted to the workpiece until the bushing shape was completed, there were deformation effect, which caused cracks and deceleration in the bushing shape. Thus, even in pre-drilling at $2.5-3 \mathrm{~mm}$ for $8 \mathrm{~mm}$ and $3.5 \mathrm{~mm}$ for $10 \mathrm{~mm}$ in diameters, at depths higher than $1 \mathrm{~mm}$, there were petal formations at the tip of the circle of bushing. As in pre-drilling friction drilling processes, when the tip of the tool passed the end of the pre-drilled hole, the tool feed and rotating motions caused even a slight deformation effect. The roundness of the bushing increases with less or without cracks and petal formation, because of the effect of the deformation is eliminated or decreased in case of the specimens are pre-drilled throughout the thickness (Demir and Ozek, 2014).

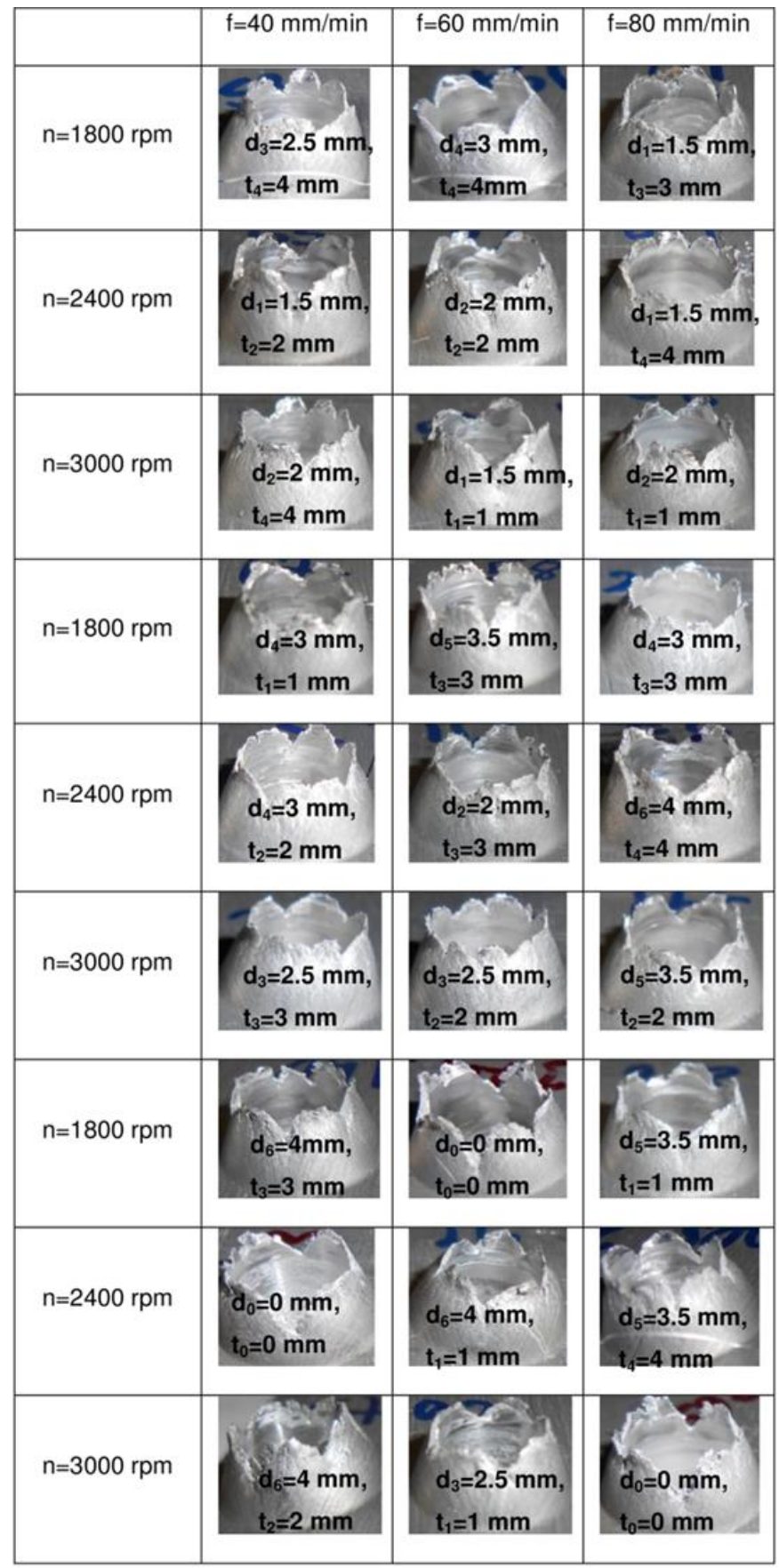

Figure 7-The bushing shapes in pre-drilling friction drilling of $8 \mathrm{~mm}$ in diameter. 


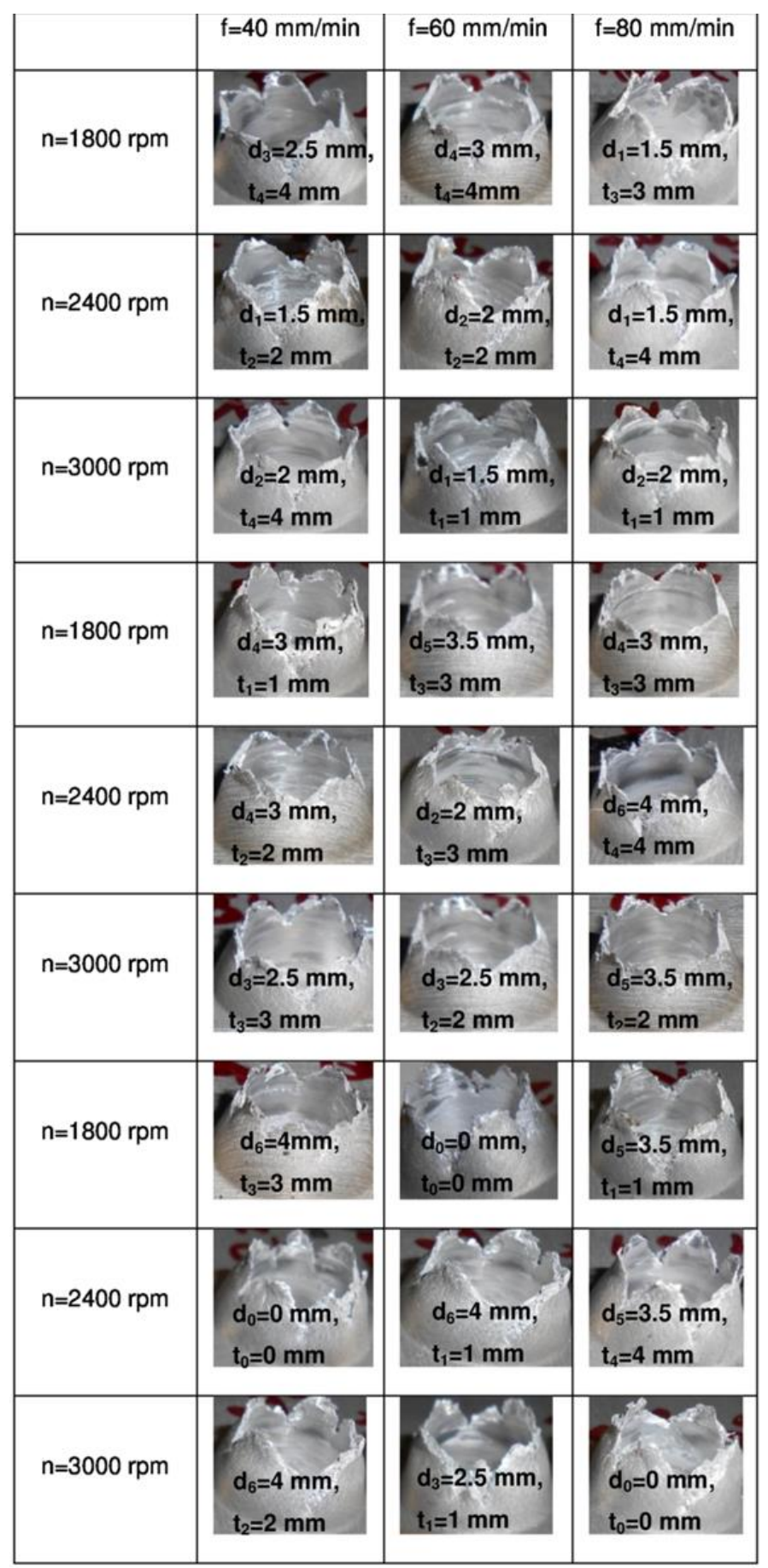

Figure 8- The bushing shapes in pre-drilling friction drilling of $10 \mathrm{~mm}$ in diameter.

\subsection{The effect of pre-drilling depths and diameters on temperature}

Friction drilling comes true by virtue of temperature, which is generated in area between tool and workpiece by the effect of friction. Frictional heat has a vital importance in friction drilling to provide melting and softening the specimens to flow. In the process, when the temperature is generated regularly, the bushing shapes occur in the form of cylindrical with less cracks and decelerations. The effect of pre-drilling depths and diameters on temperature is shown in Fig.9 for $8 \mathrm{~mm}$ (at left diagrams) and $10 \mathrm{~mm}$ (at right diagrams) in diameters pre-drilled friction drilling holes, respectively. The temperature, in case of without pre-drilled friction drilling for $8 \mathrm{~mm}$ and $10 \mathrm{~mm}$ in diameters, is shown in Fig10.

The tools were used in this experimental study, had $2.80 \mathrm{~mm}$ and $3.50 \mathrm{~mm}$ end diameters of the tips of the 
tools for $8 \mathrm{~mm}$ and $10 \mathrm{~mm}$ in diameters pre-drilled friction-drilling holes, respectively. Therefore the highest temperature recorded in friction drilling of specimens, which were pre-drilled deeper than $1 \mathrm{~mm}$ in depths, 2.5 $\mathrm{mm}$ and $3 \mathrm{~mm}$ in diameter pre-drilled for $8 \mathrm{~mm}$ (Fig. 9 at left diagrams) and $3 \mathrm{~mm}$ and $3.5 \mathrm{~mm}$ in diameter predrilled for $10 \mathrm{~mm}$ (Fig. 9 at rights diagrams) friction drilled holes, respectively. In pre-drilled friction drilling operations, applied to A7075-T651 alloy, it was investigated that $2 \mathrm{~mm}$ and bigger pre-drilling depths were appropriate. As these values were higher than $1.40 \mathrm{~mm}$ and $1.75 \mathrm{~mm}$, which were the lengths of the tips of the tools $8 \mathrm{~mm}$ and $10 \mathrm{~mm}$ in diameters, respectively, the process temperature was decreased due to the deficient of material and the effect of friction, caused to obtain frictional heat. The highest temperature was achieved in friction drilling specimens, which were pre-drilled $2.5-3 \mathrm{~mm}$ for $8 \mathrm{~mm}$ and $3-3.5 \mathrm{~mm}$ for $10 \mathrm{~mm}$ in diameters friction drilling diameters, as these pre-drilling values equal or close to the end diameter of the tip of the tools. Small pre-drilling diameters, as $2.5 \mathrm{~mm}$ for $8 \mathrm{~mm}$ (Fig. 9 (a)) and $3 \mathrm{~mm}$ for $10 \mathrm{~mm}$ in diameters friction drilling holes, were appropriate, at $1800 \mathrm{rpm}$ spindle speed, according to the temperature criterion. However, the highest temperature values were recorded at 2400 and $3000 \mathrm{rpm}$ spindle speeds in friction drilling of specimens were pre-drilled $3 \mathrm{~mm}$ (Fig. 8 (b, c, and d)) and $3.5 \mathrm{~mm}$ (Fig. 9 (b, c, and d)) in diameters for $8 \mathrm{~mm}$ and $10 \mathrm{~mm}$ in diameters friction drilled holes, respectively. In case of the diameters of pre-drilling were higher than $3 \mathrm{~mm}$ for 8 $\mathrm{mm}$ and $3.5 \mathrm{~mm}$ for $10 \mathrm{~mm}$ in diameters friction drilled holes, because of insufficient contact area between tool and workpiece, there were deficient of friction and thus the process temperature decreased. As the pre-drilling depth was bigger than $1.40 \mathrm{~mm}$ and at the same time, it got closer to this value, the initial deformation decreased and the process temperature was generated regularly.
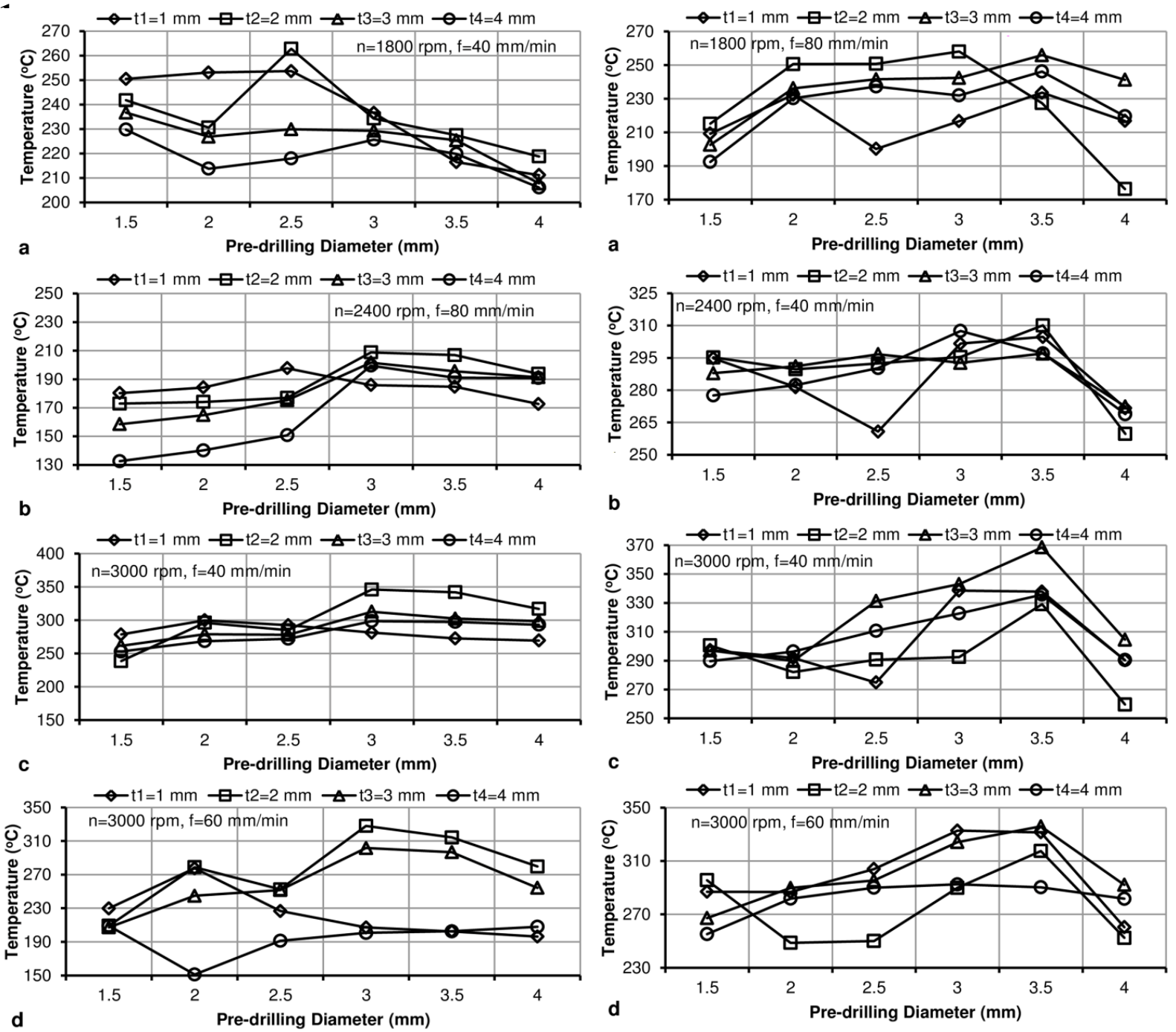

Figure 9-The effect of pre-drilling depths and diameters on temperature, $8 \mathrm{~mm}$ in diameter (at left a, b, c, d diagrams), $10 \mathrm{~mm}$ in diameter (at right a, b, c, d diagrams), friction drilled holes. 
As high spindle speeds provided more friction in contact area between tool and workpiece, because of numerous cycle of tool in per unit of feed rate, the process temperature was high. As seen in Fig. 9 with increasing the diameter of the tool, the process temperature increased, as the contact area in between tool and workpiece increased and hence the maximum temperature was obtained from $10 \mathrm{~mm}$ in diameter friction drilled holes. Additionally, the temperature increased as spindle speed increased and feed rate decreased, therefore, the highest temperature values were recorded at $3000 \mathrm{rpm}$ spindle speed and $40 \mathrm{~mm} / \mathrm{min}$ feed rate as $346.1{ }^{\circ} \mathrm{C}$ (Fig. 9 (c)) and $368.5{ }^{\circ} \mathrm{C}$ (Fig. 9 (c)) in pre-drilling friction drilling of $8 \mathrm{~mm}$ and $10 \mathrm{~mm}$ in diameters holes, in turn. However, in friction drilling, in which specimens were pre-drilled $1 \mathrm{~mm}$ in depths and in diameters smaller than $2.5 \mathrm{~mm}$ and $3 \mathrm{~mm}$ for $8 \mathrm{~mm}$ and $10 \mathrm{~mm}$ in diameters friction drilled holes, respectively. Because of initial deformation effect, the process temperature decreased.

In friction drilling, in which specimens were not pre-drilled the process temperature increased regularly with increasing spindle speeds and decreasing feed rates as seen in Fig. 10. Naturally, the highest temperature values were recorded at $3000 \mathrm{rpm}$ spindle speed and $40 \mathrm{~mm} / \mathrm{min}$ feed rates, as $286.3{ }^{\circ} \mathrm{C}$ and $298.2{ }^{\circ} \mathrm{C}$ for both $8 \mathrm{~mm}$ and $10 \mathrm{~mm}$ in friction drilled holes, respectively. Because of the effect of deformation, the temperature values were smaller than, that of recorded in pre-drilling friction drilling.

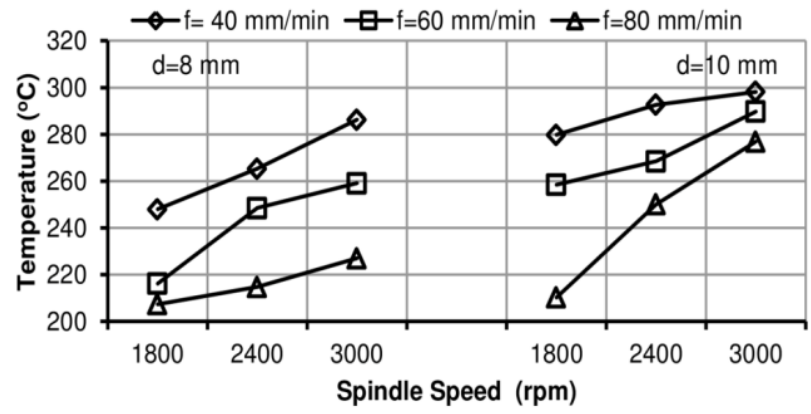

Figure 10-The temperature values in without pre-drilled friction drilling of $10 \mathrm{~mm}$ in diameter.

\section{Conclusions}

Brittle materials, such as A7075-T651 alloys, are not appropriate to achieve bushing shape in the form of cylindrical with less or without cracks in friction drilling. With the intention of improving bushing shape in friction drilling of A70759T651 alloy specimens, they were pre-drilled at four different depths and in six different diameters. Results showed that that pre-drilling diameters and depths had a vital correlation with the end diameter and length of the tip of the tool. In case of specimens were pre-drilled $2.5-3 \mathrm{~mm}$ and $3-3.5 \mathrm{~mm}$ in diameters for $8 \mathrm{~mm}$ and $10 \mathrm{~mm}$ in diameter friction drilled holes, in turn, the initial deformation was eliminated or decreased substantially and the process temperature was generated regularly. As the pre-drilling values were close to the geometrical dimensions of the tip of the tool, the highest temperature was recorded in pre-drilling friction drilling, in which specimens were pre-drilled $2 \mathrm{~mm}$ or higher in depths, $2.5 \mathrm{~mm}$ and $3 \mathrm{~mm}$ in diameters for $8 \mathrm{~mm}, 3 \mathrm{~mm}$ and $3.5 \mathrm{~mm}$ in diameters for $10 \mathrm{~mm}$ in diameter friction drilled holes.

According to the criterion of the temperature, the compliance of pre-drilling diameter changed depending on spindle speed. At $1800 \mathrm{rpm}$ spindle speed, $2.5 \mathrm{~mm}$ and $3 \mathrm{~mm}$ pre-drilling diameters for $8 \mathrm{~mm}$ and $10 \mathrm{~mm}$ in diameters friction drilled holes, respectively, were appropriate, while, at $2400 \mathrm{rpm}$ and $3000 \mathrm{rpm}$ spindle speeds, $3 \mathrm{~mm}$ and $3.5 \mathrm{~mm}$ pre-drilling diameters for $8 \mathrm{~mm}$ and $10 \mathrm{~mm}$ in diameters friction drilled holes were appropriate, respectively. The highest temperature values were recorded at $3000 \mathrm{rpm}$ spindle speed and 40 $\mathrm{mm} / \mathrm{min}$ feed rate, as $346.1{ }^{\circ} \mathrm{C}$ and $368,5^{\circ} \mathrm{C}$, in conditions specimens were pre-drilled at depth bigger than $2 \mathrm{~mm}$ and $3 \mathrm{~mm}$ and $3.5 \mathrm{~mm}$ in diameters for $8 \mathrm{~mm}$ and $10 \mathrm{~mm}$ in diameters friction drilled holes, respectively.

Despite of melting temperature, generated in contact area to cause the workpiece soften and flow, there were even smaller amount of deformation effect. Although pre-drilling depths and diameters provided decreasing or eliminating deformation, this small amount of deformation was active, until the bushing shape was completed and it caused to form small cracks and petal formation on the tip of the bushing. Therefore, on the purpose of achieving bushing shape in form of cylindrical, with less cracks and petal formation, it was recommended that specimens must be pre-drilled throughout the thickness of the material in friction drilling of brittle materials such as A7075-T651 alloy. In friction drilling of brittle materials, pre-drilling must be implement in two stages. At the first stage, specimens must be drilled throughout the thickness in small diameters such as $0.5,0.75,1,1.5$, etc. At the second stage: the upper side of the drilled hole must be drilled in depth size, equal to the length of the tip of the tool, and in diameter, equal to the end diameter of the tip of the tool. 


\section{References}

[1] Miller, S, F.; Blau, J.; Shih, A, J.; Microstructural alteration associated with friction drilling of steel, aluminium, and titanium. J. Mater. Eng. and Perform., (14) (2005) 647-653.

[2] Miller, S, F.; Tao, J.; Shih, A,J.; Friction drilling of cast metals. Int. J. Mach. Tools \& Manuf., (46) (2006) 1526-1535.

[3] Van Geffen, J.A.; Piercing Tools. US Patent 3,939,683. (1976)

[4] Van Geffen, J.A.; Method and apparatuses for forming by frictional feat and pressure holes surrounded each by a boss in a metal plate or the wall of a metal tube. US Patent 4,175,413. (1979)

[5] Chow, H.M.; Lee, S.M; Young, L.D.; Machining characteristic study of friction drilling on AISI 304 stainless steel. J. Mater. Proc. Technol., (207) (2008) 180-186.

[6] Boopathi, M.; Shankar, S.; Manikandarkumar, S.; Ramesh, R.; Experimental investigation of friction drilling on brass, aluminum and stainless steel. Procedia Eng., (64) (2013) 1219-1226.

[7] Ozler, L.; Doğru, N.; An experimental investigation of hole geometry in friction drilling. Mater. and Manuf. Proc., (28) (2013) 470-475.

[8] Lee, S, M.; Chow, H, M.; Huang, F,Y.; Yan, B, H.; Friction drilling of austenitic stainless steel by uncoated an PVD AlCrN- and TiAlN- coated tungsten carbide tools. Int. J. Mach. Tools \& Manuf., (49) (2009) 81-88.

[9] Miller, S, F.; Blau, P,.J.; Shih, A,J.; Tool wear in friction drilling. Int. J. Mach. Tools \& Manuf., (47) (2007)1636-1645.

[10] Miller, S, F.; Shih, A, J.; Thermo-mechanical finite element modelling of the friction drilling process. J. Manuf. Sci. and Eng., by ASME, (129) (2007) 531-538.

[11] Miller, S, .F.; Wang, H.; Li, R.; Shih, A,J.; Experimental and numerical analysis of the friction drilling process. ASME J. Manuf. Sci. and Eng., (128) (2008), 802-810.

[12] Kaya, M,T.; Aktas, A.; Beylergil, B.; Akyildiz, H,K.; An experimental study on friction drilling of st12 steel. Transact. Can. Soc. for Mech. Eng., (38) (2014) 319-329

[13] Demir, Z.; Ozek, C.; Investigate the effect of pre-drilling in friction drilling of A7075-T651. Mater. and Manuf. Proc., (29) (2014) 593-599. 